\title{
TRATAMENTO DO RESÍDUO RUMINAL BOVINO POR PROCESSO DE COMPOSTAGEM CONVENCIONAL
}

\section{TREATMENT OF THE BOVINE RUMINAL RESIDUE BY CONVENTIONAL COMPOSTING PROCESS}

\author{
Fabiana Lima Salomão ${ }^{1}$; Saile Dayani Farias ${ }^{2}$; Leila Maria Couto \\ Esturaro $^{1}$
}

\author{
${ }^{1}$ Universidade do Oeste Paulista - UNOSTE, Faculdade de Engenharia de Pres. \\ Prudente - FEPP \\ E-mail: fabianalsalomao@hotmail.com, leila@unoeste.br \\ ${ }^{2}$ Universidade do Oeste Paulista - UNOESTE, Faculdade de Agronomia de Pres. \\ Prudente - FAPP \\ E-mail: saile@unoeste.br
}

RESUMO - O trabalho teve como objetivo analisar a compostabilidade do resíduo ruminal bovino, incorporando esterco de galinha para fazer a adequação carbono nitrogênio. $\mathrm{Na}$ metodologia do sistema de compostagem convencional foi utilizado exclusivamente um tratamento, tendo ele, duas repetições representadas por duas leiras com composições distintas de resíduo ruminal e esterco de galinha. As proporções utilizadas em ambos os tratamentos foram $75 \%$ resíduo ruminal $+25 \%$ esterco de galinha. Os parâmetros analisados ao longo do processo de compostagem foram: $\mathrm{pH}$, umidade, temperatura, nitrogênio, carbono, relação $\mathrm{C} / \mathrm{N}$ e matéria orgânica. Os resultados obtidos ao longo do monitoramento das leiras foram similares e apresentaram características satisfatórias de qualidade de composto.

Palavras-chave: Resíduo ruminal; Compostagem; Rúmen bovino; Esterco de galinha; Composto orgânico.

ABSTRACT - The objective of this work is to analyze the compostability of the ruminal bovine residue, incorporating the chicken manure to make an adaptation to the nitrogen carbon. In the methodology of the conventional composting system a treatment was used, the two replicates represented by two lines with different compositions of ruminal residue and chicken manure. The proportions were in both treatments $75 \%$ Rumininal $+25 \%$ Range Esterco. The compounds were along the composting process: $\mathrm{pH}$, humidity, temperature, nitrogen, carbon, $\mathrm{C} / \mathrm{N}$ ratio and organic matter. The results of the monitoring

Recebido em: 26/07/2018 Revisado em: 30/07/2018 Aprovado em: 05/09/2018 were similar and showed the quality characteristics of the compound. Keywords: Ruminal residue; Composting; Bovine rumen; Chicken manur; Organic compost. 


\section{INTRODUÇÃO}

De acordo com Associação Brasileira das Indústrias Exportadoras de Carne (ABIEC, 2017) a pecuária de corte brasileira ocupa posição em destaque no mercado mundial. Desde da década de 2000, o Brasil se estabeleceu como potência na produção e exportação de carne bovina, ultrapassando países como Austrália e Estados Unidos.

Esse desenvolvimento contribui significativamente para geração de grandes quantidades resíduos sólidos e líquidos, provenientes dos processos produtivos e de transformação de carne bovina, sendo produzidos desde o abate até o produto final.

Durante o processamento de carne bovina na indústria frigorífica são gerados resíduos sólidos como: conteúdo ruminal bovino, carcaças e os resíduos líquidos: águas residuais da lavagem de carcaças e equipamentos, resíduos de sangue. Esses resíduos devem receber tratamentos específicos para que sejam dispostos sem riscos de causar impactos negativos ao meio ambiente (SANTOS; MOREIRA, 2012).

O destaque especial vai para um resíduo sólido, especificamente conhecido como: Resíduo Ruminal Bovino. Segundo Trautmann (2011) o resíduo ruminal é constituído por alimento consumido pelo animal em vários estágios de fermentação, pelo o qual permaneceu no rúmen do boi, mesmo após a dieta líquida de 24 horas antes do abate.

Nos frigoríficos, os resíduos ruminais são sobras que não possuem nenhum valor comercial e, por serem muito volumosos, apresentam dificuldades para seu descarte final, além disso, apresenta sérios problemas devido ao alto teor de matéria orgânica e nutrientes, podendo ocasionar facilmente impactos ambientais quando descartado incorretamente, por essa razão o setor frigorífico deve atender um sistema da gestão adequada para o descarte do referido resíduo (PARDI et al., 2006).

Por se tratar de um resíduo orgânico, os resíduos ruminais são passíveis de tratamento biológico. Os tratamentos biológicos podem ser realizados através do método de compostagem, sendo essa técnica uma alternativa de tratamento mais eficaz, pois a mesma possui a capacidade de transformar o resíduo sólido potencialmente poluidor em adubo orgânico.

O tratamento proporciona o aproveitamento dos resíduos gerados, possibilitando a reciclagem dos nutrientes nele encontrado, onde os mesmos passam a ser dispostos no solo na forma mineral e orgânica proporcionando melhorias nas suas características físicas, químicas e biológicas, além disso, a compostagem possui benefício inquestionável para o meio ambiente: a minimização do problema ambiental que representa no seu descarte inadequado (PIRES; MATTIAZZO, 2008).

Dessa forma, o presente trabalho teve como objetivo analisar a compostabilidade do resíduo ruminal bovino, incorporando esterco de galinha como material estruturante.

\section{METODOLOGIA}

Os experimentos foram conduzidos na unidade de compostagem inserida na Universidade do Oeste Paulista (UNOESTE), município Presidente Prudente/SP, cujas coordenadas geográficas são $22^{\circ} 7^{\prime} 4.84^{\prime \prime} \mathrm{S}$ $51^{\circ} 27^{\prime} 11.52 " \mathrm{O}$ (Figura 1).

A unidade é formada por um barracão de $150 \mathrm{~m}^{2}$, nas laterais do barracão, têm-se, em cada lado, 3 repartições limitadas por paredes de alvenaria, onde são conduzidas as valas de compostagem. Para este experimento, utilizou-se uma área provida de cobertura e piso de cimento, com vão livre que possibilitou facilitar o revolvimento $\mathrm{e}$ circulação de pessoas. 
Figura 1. Vista geral da unidade de compostagem.

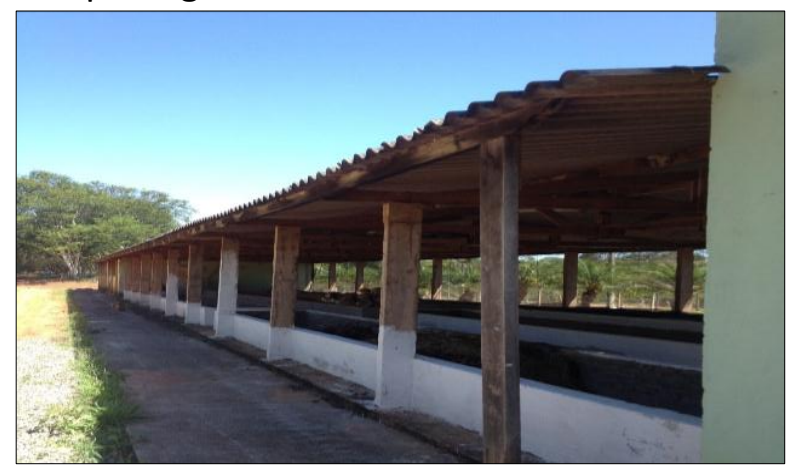

Fonte: Autores (2017).

Para composição do tratamento foi utilizado o resíduo ruminal bovino (Figura 2 A) em fase de curtimento inicial, proveniente de uma indústria frigorífica. Posteriormente o resíduo foi caracterizado quimicamente antes da efetivação da mistura com o material estruturante.

Em função da elevada relação $\mathrm{C} / \mathrm{N}$ do rúmen para o início do tratamento por compostagem, houve a necessidade de incorporação do material estruturante para adequação de tal parâmetro, optando-se pelo esterco de galinha.

$O$ esterco de galinha em fase de curtimento total (Figura 2B) foi coletado no aviário pertencente ao centro zootécnico da UNOESTE.

Figura 2. Detalhes dos materiais utilizados no sistema de compostagem.

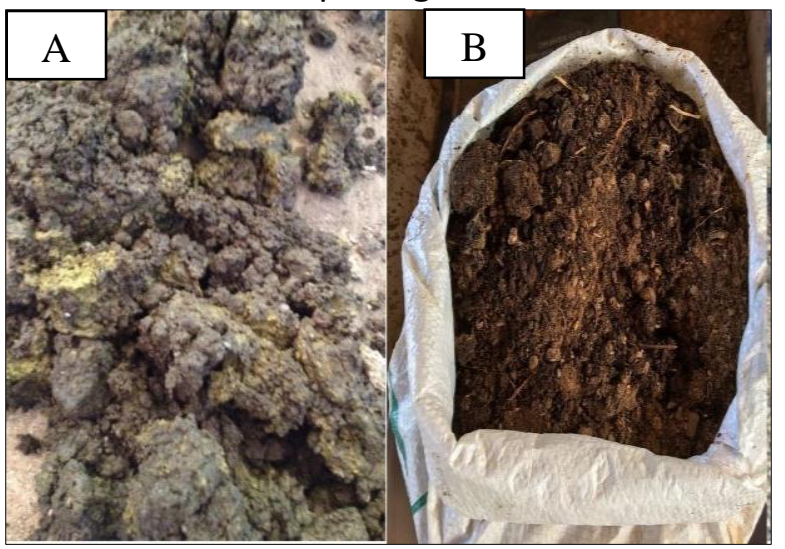

Fonte: Autores (2017).

Os experimentos do sistema de compostagem (windrow) foram constituídos por um único método de Tratamento, havendo duas repetições representadas por duas leiras (L1 e L2) contendo composições de resíduos de ruminal e esterco de galinha ( $T=75 \% R R+25 \% E G) . A$ massa total de cada leira foi de $150 \mathrm{Kg}$, sendo $112 \mathrm{Kg}$ de resíduo ruminal e $38 \mathrm{Kg}$ de material estruturante (Figura 3).

Figura 3. Composições de resíduos para o tratamento do resíduo ruminal.

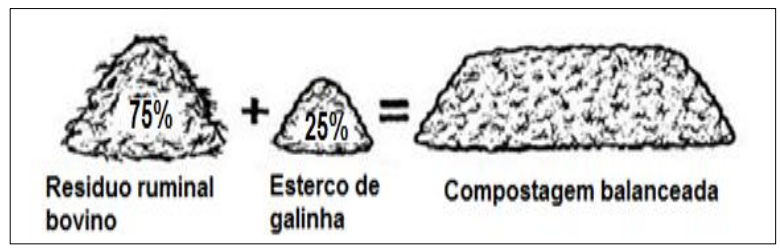

Fonte: Autores (2017).

Os resíduos foram dispostos em camadas para montagem das leiras com auxílio de pás, como observado na Figura 4.

Figura 4. Leiras de compostagem, incluindo resíduo ruminal e esterco de galinha.

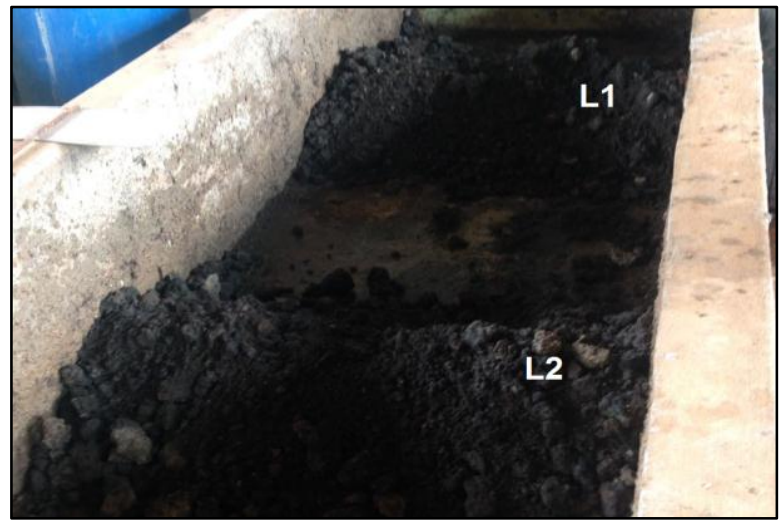

Fonte: Autores (2017).

O sistema de compostagem utilizado foi por meio do método convencional, sendo essa técnica de revolvimento manual e para a mesma foi utilizado o sistema de compostagem de pequena escala, ambas leiras possuíam as seguintes dimensões: 1,20 metros de comprimento $x 0,90$ metros de altura $\times 0,70$ metros de largura.

O monitoramento dos parâmetros físicos e químicos tiveram início em 21 de agosto de 2017 e término em 10 de novembro de 2017. Durante este período do tratamento do resíduo ruminal, foram avaliados os parâmetros com as seguintes frequências: 
Tabela 1. Parâmetros analisados durante os experimentos e suas frequências de avaliações.

\begin{tabular}{|c|c|}
\hline $\begin{array}{l}\text { Parâmetros } \\
\text { controlados }\end{array}$ & Frequência \\
\hline Umidade & Semanalmente \\
\hline Temperatura & Diariamente * \\
\hline $\mathrm{C} / \mathrm{N}$ & Início e fim \\
\hline $\mathrm{pH}$ & Início e fim \\
\hline Nitrogênio & Início e fim \\
\hline Carbono & Início e fim \\
\hline Teor de umidade & Início e fim \\
\hline
\end{tabular}

A temperatura foi monitorada com auxílio de um Termômetro Escala Interna Mercúrio $\left(-10\right.$ a $\left.110^{\circ} \mathrm{C}\right)$, as medições foram realizadas em seis pontos, a fim de se obter uma média diária da temperatura (Figura 5).

Para obtenção de melhores resultados, as medições foram padronizadas para serem realizadas no mesmo horário, local e na mesma profundidade, cerca de $\mathbf{4 0}$ $\mathrm{cm}$.

Figura 5. Termômetro utilizado e os pontos de monitoramento.

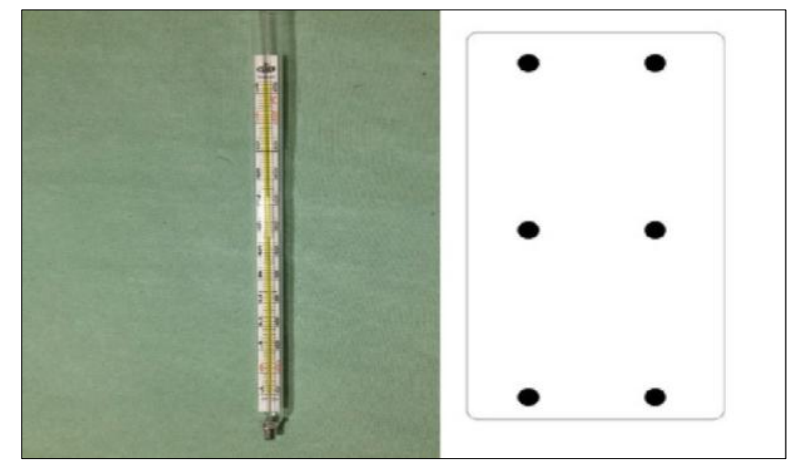

Fonte: Autores (2017).

O revolvimento consistia em tombar o material para um lado e depois retorná-lo ao seu local. Na pesquisa, o revolvimento foi feito de forma manual com o auxílio de pá e/ou inchada. As frequências de revolvimento seguiram a literatura proposta por Krom (1987) que definiu as frequências da seguinte maneira (Tabela 2 ):
Tabela 2. Frequência de revolvimento das leiras.

\begin{tabular}{cc}
\hline Semanas & $\begin{array}{c}\text { Número de } \\
\text { revolvimentos/período }\end{array}$ \\
\hline 1ㅇ a 4ㅇ & 3 vezes por semana \\
5o a 8ㅇ & 1 vez por semana \\
9o até o final da & 1 vez quinzenalmente \\
compostagem & \\
\hline Fonte: Krom (1987). &
\end{tabular}

A umidade foi monitorada a campo semanalmente através do método empírico da bolota proposto por Kiehl (2002). O controle consistia em pegar uma pequena quantidade do composto na mão e apertar, se esfarelasse o composto era molhado com auxílio de uma mangueira, caso o composto estivesse pegajoso apresentava um bom estado e se estivesse gotejando, era necessário reduzir a umidade, deixando o composto secar naturalmente, além disso, também era necessário revolver toda a leira.

Figura 6. Monitoramento da umidade através do método empírico da bolota.

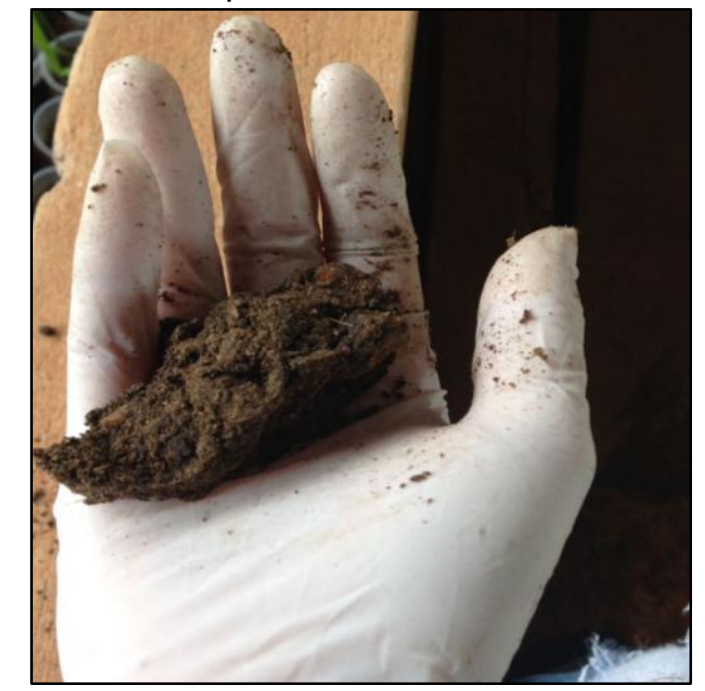

Fonte: Autores (2017). 
Figura 7. Umedecimento do composto com auxílio de mangueira.

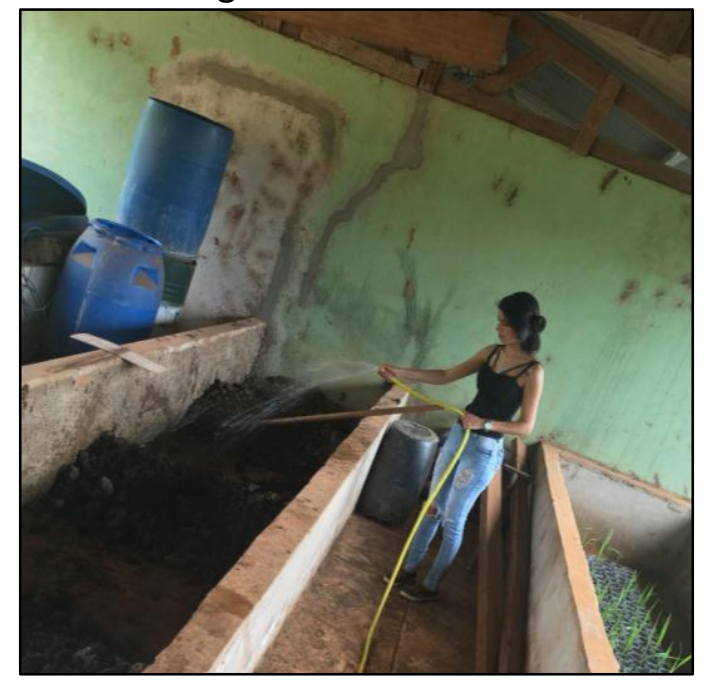

Fonte: Autores (2017).

Em relação aos parâmetros: carbono, $\mathrm{pH}$, matéria orgânica, teor de umidade, nitrogênio e relação $C / N$, tiveram controle somente no início e no final do processo de compostagem, a qual foram coletadas amostras (Figura 8) e encaminhadas para o laboratório de Análises Químicas de Tecido Vegetal - UNOESTE.

Figura 8. Amostras das leiras do sistema de compostagem.

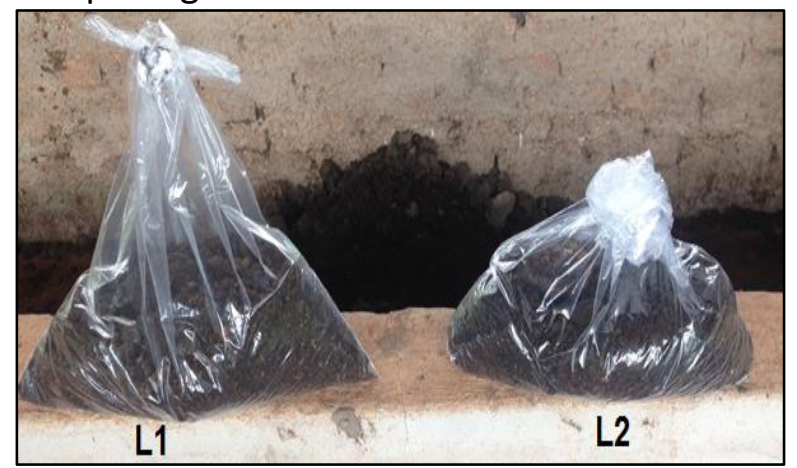

Fonte: Autores (2017).

\section{RESULTADOS}

A Tabela 3 apresenta os resultados obtidos na caracterização química inicial das leiras de compostagem.
Tabela 3. Resultados das análises químicas inicial de cada tratamento.

\begin{tabular}{ccc}
\hline \multirow{2}{*}{ Parâmetros } & \multicolumn{2}{c}{ Tratamentos } \\
\cline { 2 - 3 } & Ta & Tb \\
\hline pH & 6,9 & 6,7 \\
Umidade (\%) & 59,9 & 60,3 \\
Carbono orgânico & 44,8 & 44,3 \\
(\%) & 1,6 & 1,6 \\
Nitrogênio (\%) & 28 & 28,2 \\
Relação C/ N & 75,7 & 76,5 \\
MO (\%) &
\end{tabular}

Fonte: Autores (2017).

A Tabela 4 apresenta resultados dos compostos produzidos nos nas repetições do tratamento.

Tabela 4. Resultados dos compostos produzidos nos tratamentos.

\begin{tabular}{ccc}
\hline \multirow{2}{*}{ Parâmetros } & \multicolumn{2}{c}{ Tratamentos } \\
\cline { 2 - 3 } & Ta & Tb \\
\hline pH & 7,8 & 8 \\
Umidade (\%) & 34 & 36 \\
Carbono orgânico & 22 & 22,5 \\
(\%) & & 1,3 \\
Nitrogênio (\%) & 1,35 & 17 \\
Relação C/ N & 16 & 16,2 \\
MO (\%) & 46,4 & 44,4 \\
\hline
\end{tabular}

Fonte: Autores (2017).

\section{DISCUSSÃO}

Diante dos resultados da caracterização inicial das leiras de compostagem, os tratamentos $a$ e $b$ não apresentaram diferenças significativas entre si, visto que ambos tratamentos haviam proporções iguais de resíduos.

De acordo com Pereira Neto (2004) os valores de $\mathrm{pH}$ inicial dos tratamentos $(\mathrm{Ta}=6,9$ e $\mathrm{Tb}=6,7)$ apresentaram próximo a faixa de neutralidade (7).

Já a umidade dos tratamentos $(\mathrm{Ta}=59,9 \mathrm{tb}=60,3)$ apresentaram-se dentro das faixas satisfatórias para o início do processo de compostagem. De acordo com Richard e Woodbury (1992) a umidade 
considerada ideal para a compostagem varia entre 50 a $60 \%$.

A relação $\mathrm{C} / \mathrm{N}$ dos tratamentos apresentaram-se próxima à faixa ótima para o início do processo de compostagem, valores próximos de 30/1 (KIEHL, 1998).

Kiehl (1985) considera nível alto de teores de matéria orgânica valores superiores a $61 \%$. Assim, os tratamentos apresentaram teores de matéria orgânica altos, sendo considerado valores que favorecem o tratamento do resíduo ruminal por meio da compostagem, por ser basicamente um processo biológico de decomposição de matéria orgânica através da ação dos microrganismos.

Enquanto o resíduo ruminal "in natura" apresentava coloração verde, o material compostado apresentou coloração marrom escuro nos tratamentos (Figura 16), isso devido oxidação enzimática dos microrganismos, caracterizando a humificação (STEVENSON, 1994).

Os valores de $\mathrm{pH}$ tiveram um aumento no final do processo de compostagem e a estabilização do composto, alcançando, finalmente, os seguintes valores: 7,8 e 8. As bases científicas apontam que esses valores são considerados uma faixa ótima do $\mathrm{pH}$ para a maioria dos microrganismos (ECYCLE, 2017).

Com relação à umidade do composto humificado, as repetições apresentaram valores considerados como bons. De acordo com Kiehl (1985), que interpreta como sendo uma faixa boa os valores entre 25 e $35 \%$ de umidade no composto curado.

Já para a relação $\mathrm{C} / \mathrm{N}$, são consideradas as faixas valores entre 8 a 12 como ótimo, entre 13,1 a 18, bom e acima de 20, indesejável (KIEHL, 2008). Dessa forma, as repetições apresentaram uma relação $\mathrm{C} / \mathrm{N}$ boa.

A matéria orgânica das repetições teve redução durante 0 processo de compostagem. De acordo com Kiehl (1998) essa redução de matéria orgânica é ocasionada pelo processo de decomposição que ocorre normalmente.
O tempo de compostagem no tratamento foi de cerca 12 semanas, obtendo-se um composto estabilizado. Os resultados do composto em termos dos parâmetros $\mathrm{pH}$, umidade, carbono orgânico, nitrogênio e relação $\mathrm{C} / \mathrm{N}$ se enquadraram nos valores estabelecido pela Instrução Normativa no 25 do Ministério da Agricultura, Pecuária e Abastecimento (BRASIL, 2009).

\section{CONSIDERAÇÕES FINAIS}

A compostagem convencional é uma técnica eficaz no tratamento do resíduo ruminal bovino, sendo necessário, entretanto a adição de esterco de galinha como material estruturante, para adequação inicial do parâmetro relação $\mathrm{C} / \mathrm{N}$.

Considerando as características do composto final, conclui-se que o período de 12 semanas para o tratamento foi 0 suficiente para a transformação do resíduo em composto humificado.

O composto orgânico final em termos dos parâmetros: $\mathrm{pH}$, relação $\mathrm{C} / \mathrm{N}$, umidade, carbono e nitrogênio, $\mathrm{O}$ composto enquadrou-se como fertilizante orgânico conforme os valores estabelecidos pela Instrução Normativa no 25 Ministério da Agricultura, Pecuária e Abastecimento.

Portanto, tendo em vista os dados satisfatórios nesta pesquisa, são feitas as seguintes sugestões para futuros projetos e estudos do produto: realizar uma caracterização do composto humificado, em termos de macro e micronutrientes e verificar a eficácia deste na agricultura.

\section{REFERÊNCIAS}

ASSOCIAÇÃO BRASILEIRA DE INDÚSTRIAS EXPORTADORAS DE CARNES ABIEC. Relatório detalhado sobre as exportações de carne brasileira. Disponível em: http://www.abiec.com.br /estatisticas relatorios.asp. Acesso em: 20 ago. 2017 
ECYCLE. Qual influência do pH na compostagem. 2017. Disponível em: https://www.ecycle.com.br/. Acesso: 9 nov. 2017.

KIEHL, D. J. Adubação orgânica: 500 perguntas \& respostas. Piracicaba: DEGASPARI, 2008.

KIEHL, E. J. Fertilizantes orgânicos.

Piracicaba: Agronômica Ceres, 1985.

KIEHL, E. J. Manual de compostagem: maturação e qualidade do composto. 3.ed. São Paulo: 171 p, 2002.

KIEHL, E. J. Manual de compostagem: Maturação e qualidade do composto. Piracicaba, 1998.

KROM, V. Viabilidade econômica de uma usina de compostagem de resíduo sólido urbano. 1987. Dissertação (Mestrado em Agronomia) - Universidade Estadual Paulista, 1987.

PARDI, M. C. et al. Ciência, higiene e tecnologia da carne. 2. ed. Goiânia: UFG e Eduff, 2006.

PEREIRA NETO, J. T. Compostagem: fundamentos e métodos. In: SIMPÓSIO SOBRE COMPOSTAGEM: CIÊNCIA E TECNOLOGIA, 1., Botucatu, 2004. Anais [...]. Botucatu: Universidade Estadual Paulista, FCA., 2004.

PIRES, A. M. M.; MATTIZZO, M. E. Avaliação da viabilidade do uso de resíduos na agricultura. Jaguariúna: Embrapa Meio Ambiente, 2008. 9 p. (Circular técnica, 19).

RICHARD, T.L.; WOODBURY, P. S. The impacto $f$ separation on heavy metal contaminants in municipal solid wast compost. Biomass and Bioenergy, v.3, n.3/4, p. 195-211, 1992.

SANTOS, P.; MOREIRA, M. Tratamento orgânico de resíduos de rúmen bovino.
2012. 61f. Trabalho de conclusão do curso (Graduação em Engenharia Ambiental) - Júlio de Mesquita Filho, Universidade Estadual Paulista, Presidente Prudente - SP, 2012.

STEVENSON, F.J. Humus chemistry: genesis, composition, reactions. New York, John Wiley \& Sons, 1994.

TRAUTMANN, R. J. M. Uso de Resíduo do Rúmen bovino como fonte de nutrientes na agricultura - Benefícios agronômicos e conhecimento popular. 2011. 123 p. Dissertação (Pós-graduação em Ciências Ambientais) - Universidade Do Estado do Mato Grosso, Mato Grosso, 2011. 